\title{
Penggunaan Metode Eksperimen untuk Memahami Macam-Macam Gaya yang Bekerja pada Suatu Benda Bagi Siswa Kelas IV di SD Negeri 25 Moko Waisai Kabupaten Raja Ampat Tahun Ajaran 2018/2019
}

\author{
Khadijah $^{1}$ \\ SD Negeri 25 Moko Waisai Raja Ampat \\ azillahabiee@gmail.com
}

\begin{abstract}
Abstrak: Penelitian ini bertujuan untuk mengetahui peningkatan pemahaman siswa kelas IV SD Negeri 25 Moko Waisai Kabupaten Raja Ampat mengenai gaya yang bekerja pada benda melalui metode eksperimen. Jenis penelitian ini adalah penelitian tindakan kelas. Penelitian dilaksanakan dalam dua siklus, setiap siklus terdiri dari empat komponen yaitu perencanaan, tindakan, pengamatan dan refleksi. Teknik pengumpulan data adalah observasi, dokumentasi dan tes. Analisis data dilakukan dalam 3 tahap yaitu reduksi, penyajian data serta menarik kesimpulan. Hasil penelitian menunjukkan bahwa: (1) pemanfaatan metode ekperimen dapat meningkatkan partisipasi belajar siswa. (2) Pada Aspek mendengarkan penjelasan siklus I sebesar 93\% dan siklus II sebesar $100 \%$. Aspek mencatat penjelasan siklus 1 sebesar $68 \%$ dan siklus II sebesar 86\%. Aspek memperhatikan pembelajaran siklus I sebesar 93\% dan siklus II sebesar 100\%. Aspek bertanya siklus I sebesar $41 \%$ dan pada siklus II sebesar 68\%. Aspek menjawab pertanyaan siklus I sebesar $37 \%$ dan siklus II sebesar 75\%. Aspek mengeluarkan pendapat siklus I sebesar $62 \%$ dan pada siklus II sebesar 93\%. Aspek mampu menjelaskan kembali siklus I sebesar $79 \%$ dan pada siklus II sebesar 93\%. Hal ini menunjukkan bahwa terjadi peningkatan terhadap partisipasi aktif siswa pada Standar kompetensi memahami macam-macam gaya yang bekerja dalam kehidupan manusia. (3) Nilai rata-rata yang diperoleh siswa pada siklus I sebesar 82,03 dan meninglat menjadi sebesar 87,93 pada siklus II.
\end{abstract}

Kata kunci : Metode ekperimen, gaya pada benda, SD Negeri 25 Moko Waisai Kabupaten Raja Ampat

\begin{abstract}
The purpose of this research is to find out the improvement of students' understanding in grade IV 25 Moko Waisai Elementary School Raja Ampat Regency regarding the forces acting on objects through the experimental method. This type of research is classroom action research. The study was conducted in two cycles, each cycle consisting of four components, namely planning, action, observation and reflection. Data collection techniques are observation, documentation and testing. Data analysis was carried out in 3 stages namely reduction, presentation of data and drawing conclusions. The results showed that: (1) the use of the experimental method could increase student learning participation. (2) In the listening aspect the explanation for cycle I is $93 \%$ and cycle II is 100\%. Aspects noted explanation of cycle 1 by $68 \%$ and cycle II by $86 \%$. The aspect of paying attention to learning cycle I was $93 \%$ and cycle II was $100 \%$. The aspect of asking for the first cycle was $41 \%$ and in the second cycle it was $68 \%$. Aspects of answering the first cycle questions by $37 \%$ and the second cycle by $75 \%$. Aspects are able to explain again the first cycle by $79 \%$ and the second cycle by $93 \%$. This shows that there is an increase in the active participation of students in the Standards of competence to understand the various styles that work in human life. (3) The average value obtained by students in the first cycle was 82.03 and the increase was 87.93 in the second cycle.
\end{abstract}

Keywords: Experiment Method, force on objects, 25 Moko Waisai Elementary School Raja Ampat Regency 


\section{Pendahuluan}

Pendidikan merupakan salah satu hal penting yang harus ada pada suatu bangsa. Tujuan pendidikan yaitu mencerdaskan kehidupan bangsa dan mengembangkan manusia yang seutuhnya yaitu yang beriman dan bertakwa kepada Tuhan Yang Maha Esa dan berbudi pekerti luhur, memiliki pengetahuan dan keterampilan, kesehatan jasmani dan rohani, kepriadian yang mantap dan mandiri serta rasa tanggung jawab kemasyarakatan bangsa (UU No. 2 Tahun 1985).

Berdasarkan hal terseut tentunya sangat penting untuk melakukan peningkatan dalam bidang pendidikan. Peningkatan kemampuan siswa terdapat dalam proses belajar mengajar yang akan diterapkan oleh guru dalam pembelajaran. Muhamad Ali, (1983 : 12) yang menyebutkan bahwa kadar pembelajaran akan bermakna apabila adanya keterlibatan siswa dalam proses belajar mengajar, adanya keterlibatan intelektualemosional siswa baik melalui kegiatan menganalisa, berbuat dan pembentukan sikap dan adanya keikutsertaan siswa secara kreatif dalam menciptakan situasi yang cocok untuk berlangsungnya proses belajar mengajar.

Hal ini juga berlaku untuk diterapkan dalam pelajaran IPA khususnya pada kelas IV. Ahmad Susanti (2013: 167) mengatakan bahwa IPA adalah usaha manusia dalam memahami alam semesta melalui pengamatan yang tepat pada sasaran, serta menggunakan prosedur, dan dijelaskan dengan penalara sehingga mendapatkan suatu kesimpulan. Sebagaimana yang telah diketahui, IPA merupakan salah satu mata pelajaran yang dalam penyampaianya harus menggunakan metode pembelajaran yang tepat agar lebih efektif, dan metode ekperimen adalah salah satu motode yang cocok digunakan dalam mata pelajaran IPA. Metode ekperimen adalah cara penyajian pelajaran dimana siswa melakukan percobaan dengan mengalami dan membuktikan sendiri sesuatu yang dipelajari ( Djamarah : 1995).

Penelitian mengenai penggunaan metode ekperimen dalam mata pelajaran IPA pernah dilakukan oleh Firdaus (2012) yang berjudul Meningkatkan Pemahaman Konsep Gerak Benda dalam Pembelajaran Sains melalui Pendekatan Keterampilan Proses Siswa Kelas III SDN 169 Toribi Kabupaten Sulawesi Selatan. Hasil penelitian yang dilakukan oleh Firdaus meliputi meningkatnya kemampuan siswa dari siklus pertama yang berkisar $58,3 \%$ naik menjadi $77,3 \%$ pada siklus kedua, dan pada siklus ketiga kembali naik dan mencapai angka 84\%. Metode yang digunakan dalam penelitian yang dilakukan oleh Firdaus yaitu menggunaan pendekatan keterampilan proses siswa, dan Firdaus menjadikan siswa kelas III SD sebagai objek penelitian.

Penelitian selanjutnya dilakukan oleh Maria (2014) yang berjudul Penggunaan Metode Ekperimen Untuk Meningkatkan Hasil Belajar Siswa Kelas IV SDN Tapis Tembawang. Hasil penelitian yang dilakukan oleh Maria adalah bahwa penggunaan metode ekperimen dapat meningkatkan hasil belajar siswa saat mengikuti pembelajaran IPA yang dapat dilihat pada siklus I berada pada angka $66,67 \%$ dan pada siklus II meningat menjadi $91,67 \%$ yang jika dihitung terjadi peningkatan sekitar $25 \%$. Penelitian yang dilakukan oleh Maria menggunakan metode ekperimen dan fokus masalah dalam penelitian Marian yaitu pada materi pembelajaran IPA secara keseluruhan, dan objek penelitian yang dilakukan Maria adalah siswa kelas V SD. 


\section{Metode Penelitian}

Penelitian ini merupakan penelitian tindakan kelas (classroom action research), yaitu pencermatan terhadap kegiatan belajar berupa sebuah tindakan, yang sengaja dimunculkan dan terjadi dalam sebuah kelas secara bersama. Penelitian ini dilakukan secara mandiri yaitu langkah demi langkah. Peneliti juga berperan sebagai guru di dalam kelas yang menerapkan secara langsung penelitian tindakan kelas kepada siswa dengan menggunakan standar kompetensi yang telah ditentukan yaitu Memahami MacamMacam Gaya, Antara Lain Gaya Otot, Gaya Listrik, Gaya Magnet, Gaya Gravitasi, Dan Gaya Gesekan dengan tujuan memperbaiki kekurangan-kekurangan dalam praktik pembelajaran.

Dalam penelitian ini, guru bertindak sebagai pelaksana tindakan sekaligus pengamat tindakan kelas. Dalam penelitian ini mencoba menerapkan model pembelajaran menggunakan metode ekperimen. Dalam penelitian tindakan kelas ini terdiri atas rangkaian empat kegiatan yang dilakukan dalam siklus berulang. (1) Perencanaan; (2) Tindakan; (3) observasi; (4) Refleksi. Tempat penelitian dilaksanakan di SD Negeri 25 Moko Wisai Kabupaten, Raja Ampat yang beralamat di jalan pendidikan Perumahan 200 Moko, Waisai. Pemilihan SD Negeri 25 Moko Wisai, Kabupaten Raja Ampat, karena belum dimanfaatkannya metode ekperimen untuk pembelajaran pada Ilmu Pengetahuan Alam (IPA). Waktu penelitian dilaksanakan pada tanggal 04 Februari 2019 sampai dengan 03 Juni 2019.

Subjek dalam penelitian ini adalah siswa kelas IV SD Negeri 25 Moko Wisai Kabupaten, Raja Ampat. Sedangkan yang menjadi objek penelitian adalah memahami macam-macam gaya yang bekerja pada benda pemanfaatan metode ekperimen. Teknik pengumpulan data yang dilakukan adalah menggunakan teknik observasi menggunakan lembar observasi/pengamatan, pemberian tes pada dan akhir siklus (post-test), dan dokumentasi. Dalam penelitian ini menggunakan dua siklus. Yaitu siklus I dan siklus II.

\section{Hasil dan Pembahasan Kondisi Awal dan Perencanaan}

Dari hasil pengamatan yang dilakukan prestasi belajar pada mata pelajaran IPA siswa kelas IV di SD Negeri 25 Moko Waisai, Kabupaten. Raja Ampat dikatakan rendah karena masih ada 18 siswa yang mendapatkan nilai di bawah 6.0 yang merupakan Kriteria Ketuntasan Minimal (KKM) yang telah ditentukan sekolah dengan melihat hasil ulangan harian. Hal ini disebabkan guru masih menggunakan metode yang tidak menarik dan monoton sehingga siswa menjadi pasif dan kurang aktif dalam mengikuti proses pembelajaran. Hal ini apabila tidak ditindaklanjuti tentu akan berakibat pada proses pembelajaran yang tidak optimal dan akan mempengaruhi prestasi belajar siswa. Untuk itu dilakukanlah penelitian siklus I yang menerapkan metode pembelajaran ekperimen untuk kompetensi dasar mengidentifikasi macam-macam gaya, antara lain: gaya otot, gaya listrik, gaya magnet, gaya gravitasi, dan gaya gesekan. 


\section{- Hasil Siklus I}

Tabel 1. Hasil Observasi Partisipasi Aktif Siswa pada Siklus I

\begin{tabular}{lccc} 
& Jumlah & \multicolumn{2}{c}{ Partisipasi Aktif } \\
\cline { 3 - 4 } \multicolumn{1}{c}{ Aspek Yang Diamati } & Siswa & Jumlah & Persentase \\
& Total & Siswa & \\
\hline Mendengarkan Penjelasan & 29 & 27 & $93 \%$ \\
Mencatat Penjelasan & 29 & 20 & $68 \%$ \\
Memperhatikan Pembelajaran & 29 & 27 & $93 \%$ \\
Bertanya & 29 & 12 & $41 \%$ \\
Menjawab Pertanyaan & 29 & 11 & $37 \%$ \\
Mengeluarkan Pendapat & 29 & 18 & $62 \%$ \\
Menghargai Pendapat Teman & 29 & 25 & $86 \%$ \\
Mampu Menjelaskan Kembali & 29 & 23 & $\mathbf{7 9 \%}$ \\
\hline \multicolumn{1}{c}{ Jumlah } & \multicolumn{3}{c}{$\mathbf{1 6 3}$} \\
\hline \multicolumn{1}{c}{ Rata-rata } & $\mathbf{5 5 9 \%}$ & $\mathbf{6 9 . 8 7 \%}$ \\
\hline
\end{tabular}

Berdasarkan hasil observasi partisipasi aktif siswa pada siklus I, dapat dilihat pada Tabel 1 dikatakan bahwa tingkat partisipasi aktif siswa masih rendah, meskipun telah menyentuh angka 60\% secara keseluruhan. Namun hal ini tentunya berdampak pada prestasi belajar siswa. Hal ini dapat dilihat pada perolehan nilai yang didapat oleh siswa kelas IV SD Moko Waisai Kabupaten Raja ampat, yang dapat dilihat pada Tabel 2:

Tabel 2. Hasil Perhitungan Tes pada Siklus I

\begin{tabular}{clccc} 
No & \multicolumn{1}{c}{ Nama Siswa } & Kkm & Tes Siklus II & Ketuntasan \\
\hline & & & & \\
1 & Andi Wenny Vrida Sistayana & 60 & 92 & Tuntas \\
2 & Adir Djansen Ristopel Imbir & 60 & 50 & Tidak Tuntas \\
3 & Bayu Husain Bakir & 60 & 93 & Tuntas \\
4 & Haterine Bernesi Kapitan Laut & 60 & 95 & Tuntas \\
5 & Demianus Mauradi Korwa & 60 & 85 & Tuntas \\
6 & Faini Hana Omkarsba & 60 & 94 & Tuntas \\
7 & Gilbert Esau Dimara & 60 & 90 & Tuntas \\
8 & Galya Apnesya Rosay & 60 & 88 & Tuntas \\
9 & Hobertina Sauyai & 60 & 90 & Tuntas \\
10 & Ismail Wildan Tamima & 60 & 88 & Tuntas \\
11 & Jenni Elina Sauyai & 60 & 59 & Tidak Tuntas \\
12 & Jekris Juandris Laitera & 60 & 82 & Tuntas \\
13 & Khairinnida Rappan & 60 & 93 & Tuntas \\
14 & La Ode Sahrul & 60 & 58 & Tidak Tuntas \\
15 & Marinda Natalia Dotiri & 60 & 92 & Tuntas \\
16 & Miranda Olivia Dotiri & 60 & 88 & Tuntas \\
17 & Moiren Lesty Sari Pureng & 60 & 92 & Tuntas \\
18 & Reza Charles Gibson Kapisa & 60 & 59 & Tidak Tuntas \\
19 & Maulana M. S. Lewataka & 60 & 92 & Tuntas \\
20 & Rafi Febrian Ratusehaka & 60 & 90 & Tuntas
\end{tabular}




\begin{tabular}{|c|c|c|c|c|}
\hline 21 & Tiaratul Husna & 60 & 95 & Tuntas \\
\hline 22 & Toyo Salomo Korano Ayomi & 60 & 92 & Tuntas \\
\hline 23 & Tri Karlina S. Sauyai & 60 & 95 & Tuntas \\
\hline 24 & Virginia Mina Bety Imbir & 60 & 80 & Tuntas \\
\hline 25 & Vina Gracia Salamor & 60 & 58 & Tidak Tuntas \\
\hline 26 & Wasti Agnes Wanma & 60 & 70 & Tuntas \\
\hline 27 & Zhelin Sauyai & 60 & 75 & Tuntas \\
\hline 28 & I Made Darma Guna & 60 & 89 & Tuntas \\
\hline 29 & Musa & 60 & 55 & Tidak Tuntas \\
\hline & $\sum$ Nilai & \multicolumn{3}{|c|}{2379} \\
\hline & Rata-Rata & \multicolumn{3}{|c|}{82.03} \\
\hline & Nilai Tertinggi & \multicolumn{3}{|c|}{95} \\
\hline & Nilai Terendah & \multicolumn{3}{|c|}{$\mathbf{5 0}$} \\
\hline
\end{tabular}

Pada tabel 2 hasil perhitungan siklus I rata-rata siswa pada post test 1 dapat diketahui sebesar 82.03 dan didapat dengan menggunakan rumus yang dikembangkan oleh Arikunto (2009: 264) dalam bukunya dasar-dasar evaluasi pendidikan: $\mathrm{X}=\frac{\Sigma}{N}$. Hal ini menunjukkan bahwa terjadi peningkatan hasil belajar siswa setelah menggunakan metode ekperimen dalam mata pelajaran IPA. Namun berdasarkan nilai siswa pada siklus I di atas, kriteria keberhasilan belum tercapai, sebab masih terdapat 6 siswa belum mencapai KKM, sehingga perlu dilanjutkan dengan siklus berikutnya yaitu siklus II.

\section{- Siklus II}

Tabel 3. Hasil Observasi Partisipasi Aktif Siswa pada Siklus II

\begin{tabular}{|c|c|c|c|}
\hline \multirow[b]{2}{*}{ Aspek Yang Diamati } & \multirow{2}{*}{$\begin{array}{c}\text { Jumlah } \\
\text { Siswa } \\
\text { Total }\end{array}$} & \multicolumn{2}{|c|}{ Partisipasi Aktif } \\
\hline & & $\begin{array}{c}\text { Jumlah } \\
\text { Siswa }\end{array}$ & Persentase \\
\hline Mendengarkan Penjelasan & 29 & 29 & $100 \%$ \\
\hline Mencatat Penjelasan & 29 & 25 & $86 \%$ \\
\hline Memperhatikan Pembelajaran & 29 & 29 & $100 \%$ \\
\hline Bertanya & 29 & 20 & $68 \%$ \\
\hline Menjawab Pertanyaan & 29 & 22 & $75 \%$ \\
\hline Mengeluarkan Pendapat & 29 & 27 & $93 \%$ \\
\hline Menghargai Pendapat Teman & 29 & 26 & $89 \%$ \\
\hline Mampu Menjelaskan Kembali & 29 & 27 & $93 \%$ \\
\hline Jumlah & & 205 & $\mathbf{7 7 5 \%}$ \\
\hline Rata-Rata & & 25.62 & $96.87 \%$ \\
\hline
\end{tabular}

Berdasarkan hasil observasi partisipasi aktif siswa pada Tabel 3, dapat dikatakan bahwa tingkat partisipasi siswa meningkat dengan sangat baik. Hal ini terlihat pada rata-rata partisipasi aktif siswa telah menyentuh angka $90 \%$ yang artinya hampir semua siswa kelas IV SD Moko Waisai Kabupaten Raja Ampat telah mampu berpartisipasi secara aktif dalam proses belajar mengajar di dalam kelas sebagai akibat dari penggunaan metode ekperimen pada mata pelajaran IPA. 
Dampak yang baik juga terlihat pada prestasi belajar siswa yang tampak pada Tabel 4:

Tabel 4. Hasil Perhitungan Tes pada Siklus II

\begin{tabular}{|c|c|c|c|c|}
\hline No & Nama Siswa & $\mathrm{Kkm}$ & Tes Siklus II & Ketuntasan \\
\hline 1 & Andi wenny vrida sistayana & 60 & 100 & Tuntas \\
\hline 2 & Adir djansen ristopel imbir & 60 & 75 & Tuntas \\
\hline 3 & Bayu Husain bakir & 60 & 95 & Tuntas \\
\hline 4 & Haterine bernesi kapitan laut & 60 & 98 & Tuntas \\
\hline 5 & Demianus mauradi korwa & 60 & 85 & Tuntas \\
\hline 6 & Faini Hana Omkarsba & 60 & 98 & Tuntas \\
\hline 7 & Gilbert Esau Dimara & 60 & 94 & Tuntas \\
\hline 8 & Galya Apnesya Rosay & 60 & 89 & Tuntas \\
\hline 9 & Hobertina Sauyai & 60 & 93 & Tuntas \\
\hline 10 & Ismail Wildan Tamima & 60 & 88 & Tuntas \\
\hline 11 & Jenni Elina Sauyai & 60 & 79 & Tuntas \\
\hline 12 & Jekris Juandris Laitera & 60 & 85 & Tuntas \\
\hline 13 & Khairinnida Rappan & 60 & 95 & Tuntas \\
\hline 14 & La Ode Sahrul & 60 & 80 & Tuntas \\
\hline 15 & Marinda Natalia Dotiri & 60 & 95 & Tuntas \\
\hline 16 & Miranda Olivia Dotiri & 60 & 90 & Tuntas \\
\hline 17 & Moiren Lesty Sari Pureng & 60 & 95 & Tuntas \\
\hline 18 & Reza Charles Gibson Kapisa & 60 & 77 & Tuntas \\
\hline 19 & Maulana M. S. Lewataka & 60 & 90 & Tuntas \\
\hline 20 & Rafi Febrian Ratusehaka & 60 & 95 & Tuntas \\
\hline 21 & Tiaratul Husna & 60 & 99 & Tuntas \\
\hline 22 & Toyo Salomo Korano Ayomi & 60 & 95 & Tuntas \\
\hline 23 & Tri Karlina S. Sauyai & 60 & 98 & Tuntas \\
\hline 24 & Virginia Mina Bety Imbir & 60 & 85 & Tuntas \\
\hline 25 & Vina Gracia Salamor & 60 & 59 & Tidak Tuntas \\
\hline 26 & Wasti Agnes Wanma & 60 & 88 & Tuntas \\
\hline 27 & Zhelin Sauyai & 60 & 80 & Tuntas \\
\hline 28 & I Made Darma Guna & 60 & 92 & Tuntas \\
\hline 29 & Musa & 60 & 58 & Tidak Tuntas \\
\hline & $\sum$ Nilai & & \multicolumn{2}{|c|}{2550} \\
\hline & Rata-Rata & & \multicolumn{2}{|c|}{87.93} \\
\hline & Nilai Tertinggi & & \multicolumn{2}{|c|}{100} \\
\hline & Nilai Terendah & & \multicolumn{2}{|c|}{58} \\
\hline
\end{tabular}

Pada tabel hasil perhitungan siklus II di atas, rata-rata siswa pada post test 2 dapat diketahui sebesar 87.93. Hal ini menunjukkan bahwa terjadi peningkatan hasil belajar siswa setelah menggunakan metode ekperimen dalam mata pelajaran IPA. Berdasarkan tabel di atas, hanya terdapat 2 siswa yang masih memiliki nilai di bawah KKM. Namun jika dilihat secara keseluruhan, pada siklus II sudah menunjukan keberhasilan penggunaan metode ekperimen. Untuk itu, peneliti memutuskan untuk tidak melanjutkan pada siklus III. 


\section{Peningkatan Partisipasi Aktif dan Prestasi Belajar Siswa}

Dari kedua siklus yang telah dilakukan yaitu siklus I dan siklus II, pada partisipasi aktif siswa dan prestasi belajar siswa sama-sama mengalami peningkatan. Proses peningkatan keduanya dapat dilihat pada Tabel 5:

Tabel 5. Peningkatan Partisipasi Aktif Siklus I dan Siklus II

\begin{tabular}{lccc}
\multicolumn{1}{c}{ Aspek Yang Diamati } & Siklus I & Siklus II & $\begin{array}{c}\text { Peningkatan } \\
\text { Partisipasi }\end{array}$ \\
\hline Mendengarkan Penjelasan & $93 \%$ & $100 \%$ & $7 \%$ \\
Mencatat Penjelasan & $68 \%$ & $86 \%$ & $18 \%$ \\
Memperhatikan Pembelajaran & $93 \%$ & $100 \%$ & $7 \%$ \\
Bertanya & $41 \%$ & $68 \%$ & $27 \%$ \\
Menjawab Pertanyaan & $37 \%$ & $75 \%$ & $38 \%$ \\
Mengeluarkan Pendapat & $62 \%$ & $93 \%$ & $31 \%$ \\
Menghargai Pendapat Teman & $86 \%$ & $89 \%$ & $3 \%$ \\
Mampu Menjelaskan Kembali & $\mathbf{7 9 \%}$ & $93 \%$ & $14 \%$ \\
\hline \multicolumn{1}{c}{ Jumlah } & $\mathbf{5 5 9 \%}$ & $\mathbf{7 7 5 \%}$ & $\mathbf{1 4 5 \%}$ \\
$\quad$ Rata-Rata & $\mathbf{6 9 . 8 7 \%}$ & $\mathbf{9 6 . 8 7 \%}$ & $\mathbf{8 3 . 3 7 \%}$ \\
\hline
\end{tabular}

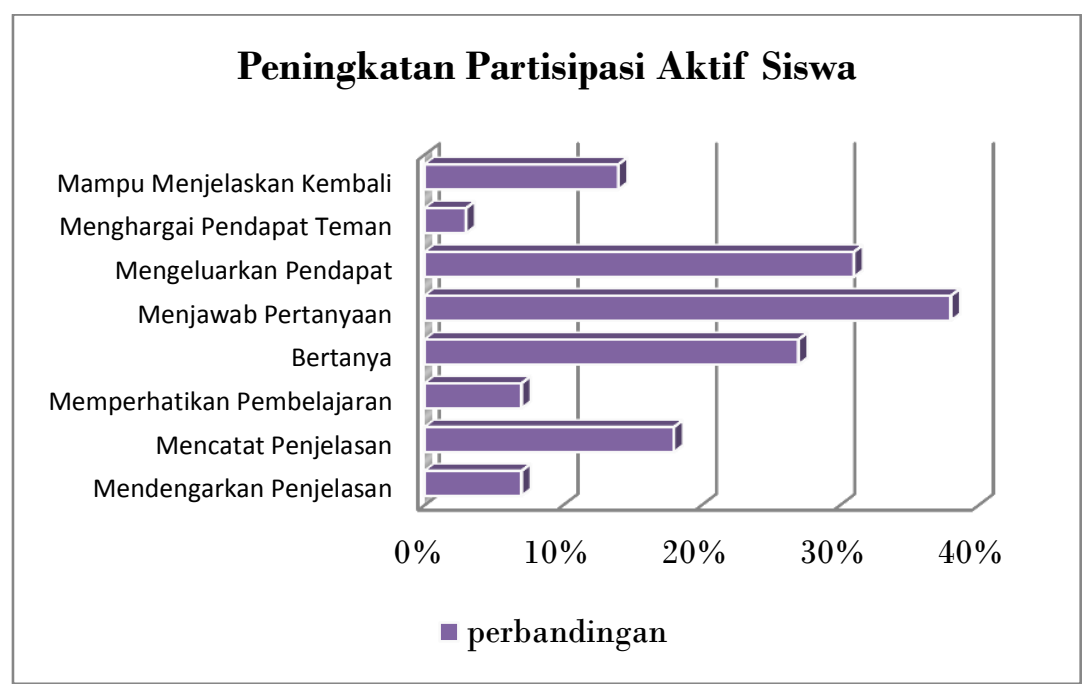

Gambar 1. Peningkatan Partisipasi Aktif Siswa

Pada Tabel 5 dan Gambar 1 dapat disimpulkan peningkatan tertinggi terjadi pada proses menjawab pertanyaan yang mencapai 38\%. Sebaliknya proses peningkatan paling rendah terjadi pada proses mengharga pendapat teman yaitu sebesar 3\%. Meskipun begitu secara keseluruhan partisipasi aktif siswa dalam proses belajar mengajar dari siklus I menuju siklus II dapat dikatakan berhasil karena telah mencapai tujuan peneliti yaitu untuk mengetahui peningkatan pemahaman siswa kelas IV di SD Negeri 25 Moko Waisai Kabupaten Raja Ampat, mengenai macam-macam gaya yang bekerja pada benda. 
Sedangkan untuk prestasi belajar siswa juga mengalami peningkatan yang sangat baik. Hal ini dapat diperhatikan pada Tabel 6:

Tabel 6. Hasil Perhitungan Tes pada Siklus 1 dan Siklus II

\begin{tabular}{|c|c|c|c|}
\hline No & Nama Siswa & Tes Siklus I & Tes Siklus II \\
\hline 1 & Andi wenny vrida sistayana & 92 & 100 \\
\hline 2 & Adir djansen ristopel imbir & 50 & 75 \\
\hline 3 & Bayu Husain bakir & 93 & 95 \\
\hline 4 & Haterine bernesi kapitan laut & 95 & 98 \\
\hline 5 & Demianus mauradi korwa & 85 & 85 \\
\hline 6 & Faini Hana Omkarsba & 94 & 98 \\
\hline 7 & Gilbert Esau Dimara & 90 & 94 \\
\hline 8 & Galya Apnesya Rosay & 88 & 89 \\
\hline 9 & Hobertina Sauyai & 90 & 93 \\
\hline 10 & Ismail Wildan Tamima & 88 & 88 \\
\hline 11 & Jenni Elina Sauyai & 59 & 79 \\
\hline 12 & Jekris Juandris Laitera & 82 & 85 \\
\hline 13 & Khairinnida Rappan & 93 & 95 \\
\hline 14 & La Ode Sahrul & 58 & 80 \\
\hline 15 & Marinda Natalia Dotiri & 92 & 95 \\
\hline 16 & Miranda Olivia Dotiri & 88 & 90 \\
\hline 17 & Moiren Lesty Sari Pureng & 92 & 95 \\
\hline 18 & Reza Charles Gibson Kapisa & 59 & 77 \\
\hline 19 & Maulana M. S. Lewataka & 92 & 90 \\
\hline 20 & Rafi Febrian Ratusehaka & 90 & 95 \\
\hline 21 & Tiaratul Husna & 95 & 99 \\
\hline 22 & Toyo Salomo Korano Ayomi & 92 & 95 \\
\hline 23 & Tri Karlina S. Sauyai & 95 & 98 \\
\hline 24 & Virginia Mina Bety Imbir & 80 & 85 \\
\hline 25 & Vina Gracia Salamor & 58 & 59 \\
\hline 26 & Wasti Agnes Wanma & 70 & 88 \\
\hline 27 & Zhelin Sauyai & 75 & 80 \\
\hline 28 & I Made Darma Guna & 89 & 92 \\
\hline 29 & Musa & 55 & 58 \\
\hline & $\sum$ Nilai & 2379 & 2550 \\
\hline & Rata-Rata & 82.03 & 87.93 \\
\hline & Nilai Tertinggi & 95 & 100 \\
\hline & Nilai Terendah & 50 & 58 \\
\hline
\end{tabular}

Dari hasil perhitungan dan perbandingan prestasi belajar siswa kelas IV SD Moko Waisai Kabupaten Raja Ampat, semua siswa mengalami peningkatan, meskipun 2 siswa diantaranya belum mampu mencapai nilai KKM. Meskipun begitu hal ini menjadi bukti bahwa penggunaan metode ekperimen untuk mata pelajaran IPA kelas IV dengan materi macam-macam gaya yang bekerja pada benda, dapat dikatakan berhasil karena terjadi peningkatan, baik pada partisipasi aktif siswa maupun prestasi belajar siswa. 


\section{Kesimpulan dan Saran \\ 4.1. Kesimpulan}

Berdasarkan hasil analisis data dan pembahasan yang telah peneliti lakukan, aktivitas belajar siswa kelas IV di SD Negeri 25 Moko Waisai, Kabupaten Raja Ampat untuk mata pelajaran IPA, dapat ditarik kesimpulan sebagai berikut: (1) Penerapan pembelajaran dengan menggunakan metode ekperimen dapat membantu siswa untuk memahami macam-macam gaya yang bekerja pada suatu benda pada matapelajaran IPA siswa kelas IV dilihat dari adanya peningkatan persentase; (2) Peningkatannya dapat dilihat dari hasil observasi pada siklus I dan siklus II. Pada Aspek mendengarkan penjelasan siklus I sebesar 93\% dan siklus II sebesar 100\%. Aspek mencatat penjelasan siklus I sebesar $68 \%$ dan siklus II sebesar $86 \%$. Aspek memperhatikan pembelajaran siklus I sebesar 93\% dan siklus II sebesar 100\%. Aspek bertanya siklus I sebesar 41\% dan pada siklus II sebesar $68 \%$. Aspek menjawab pertanyaan siklus I sebesar $37 \%$ dan siklus II sebesar 75\%. Aspek mengeluarkan pendapat siklus I sebesar $62 \%$ dan pada siklus II sebesar 93\%. Aspek menghargai pendapat teman siklus I sebesar $86 \%$ dan pada siklus II sebesar 89\%. Aspek mampu menjelaskan kembali siklus I sebesar $79 \%$ dan pada siklus II sebesar 93\%. Hal ini menunjukkan bahwa terjadi peningkatan terhadap partisipasi aktif siswa pada Standar kompetensi memahami macam-macam gaya yang bekerja dalam kehidupan manusia; (3) Metode ekperimen juga dapat meningkatkan hasil belajar pada mata pelajaran IPA di kelas. Peningkatan hasil belajar ini dapat dilihat dari adanya perubahan nilai rata-rata yang diperoleh siswa pada setiap akhir siklus. Nilai ratarata yang diperoleh siswa pada siklus I sebesar 82,03 dan siklus II sebesar 87,93. Hal tersebut membuktikan bahwa dengan menggunakan metode ekperimen dapat meningkatkan prestasi belajar siswa.

\subsection{Saran}

Berdasarkan hasil penelitian, pembahasan dan kesimpulan di atas, disarankan agar guru perlu mengupayakan partisipasi belajar siswa dengan cara melanjutkan pembuatan metode ekperimen pada mata pelajaran IPA untuk pertemuan-pertemuan selanjutnya agar siswa tertarik dalam memahami materi yang diberikan dalam proses pembelajaran sehingga partisipasi siswa dapat bertahan bahkan meningkat.

\section{Daftar Pustaka}

Ali, M. (1983). Guru dalam Proses Belajar Mengajar. Bandung: Sinar Baru Algesindo. Arikunto, Suharsimi. (2009). Manajemen Penelitian. Jakarta: PT. Rineka Cipta. Firdaus. 2012. Meningkatkan Pemahaman Konsep Gerak Benda dalam Pembelajaran Sains melalui Pendekatan Keterampilan Proses Siswa Kelas III SDN 169 Toribi Kabupaten Sulawesi Selatan. Makasar.

Maria, Leni. 2014. Peggunaan Metode Ekperimen Untuk Meningkatkan Hail Belajar Siswa Kelas IV SDN 43 Tapis Tembawang. Pontianak: Universitas Tanjungpura.

Susanto, Ahmad. (2013). Teori Belajar dan Pembelajaran di Sekolah Dasar. Jakarta: Kencana Prenada Media Group.

Djamarah, S. B. \& Zain, A. (2002). Strategi Belajar Mengajar. Jakarta: Rineka Cipta. 